\title{
Polyamide 12/E-glass Fabric Composite Production with Dip-coating
}

\author{
Aylin Bekem*, and Ahmet Unal \\ Yildiz Technical University, Department of Metallurgical and Materials Engineering, 34220, Esenler, \\ Istanbul, Turkey
}

\begin{abstract}
In this study PA12 was reinforced with E-glass woven fabric by dip-coating. PA12 powder and ethanol suspensions were prepared with ratios at 30, 40 and $50 \%$ of powder to obtain different fibre contents. Coated fabrics were laid-up and kept in oven at $60^{\circ} \mathrm{C}$ to evaporate ethanol. Then it was placed in a compression mould and pressed. Obtained laminates were subjected to tensile, bending and impact tests. Fractured surfaces were observed. It was found that mechanical properties were highest when $40 \%$ PA powder used in suspension with dip-coating with additional lamination. Fibre failure and fibre pull-out were observed on fractured surfaces.
\end{abstract}

\section{Introduction}

Thermoplastic composites have some advantages over thermoset composites with higher strain, chemical durability, lower water absorption, recyclability, etc. [1]. Polyamide (PA) is one thermoplastic polymer, also used in composites as matrix. It has applications in automotive, electrical and electronic, and packaging industries [2]. In these industries, most used types are PA6 and PA66 which are the toughest types. However, there are various types of polyamides showing different properties. Among them, PA12 has lowest water absorption, besides it has good chemical resistance and high impact resistance and toughness.

The studies of polyamide composites are generally on short fibre reinforcement [3-5] and long fibre reinforcement [6-8] that are processed in extrusion or/and injection moulding lean on melt compounding. However only limited numbers of studies have focused on woven fabric reinforcement [9].

In this study, E-glass woven fabric reinforced PA matrix was produced. E-glass woven fabric was impregnated in PA powder/ethanol suspensions at 30, 40 and 50\% PA ratios. Suspension was applied by spraying and dip-coating. Also dip-coating procedure implemented by two ways: with/without additional lamination. The final step was pressing for consolidation for all. Produced samples were burned out to determine fibre volume ratio. Tensile, bending and impact test was performed to obtain mechanical properties. Fractures surfaces were investigated with Scanning Electron Microscope (SEM).

\footnotetext{
* Corresponding author: aylinaltinbay@gmail.com
} 


\section{Experimental}

PA12 was reinforced with E-glass woven fabric. Spraying and dip-coating was applied to fabric. PA12 powder and ethanol suspensions were prepared with ratios at 30, 40 and $50 \%$ of powder to obtain different fibre contents. To prevent collapsing of PA particles in suspension, stirring was applied to suspension constantly. Three production procedures were applied. These were spraying suspension to fabric, dipping fabric to suspension and additionally laminate each layer before pressing, and dipping and directly pressing without lamination. Impregnated fabrics were laid-up and kept in oven at $60^{\circ} \mathrm{C}$ to evaporate ethanol. Then these were placed in a compression mould and pressed at $200^{\circ} \mathrm{C}$ for 3 minutes and following another 3 minutes at ambient temperature. Obtained composites were subjected to burned out, tensile, bending and impact tests. Fractured surfaces were observed.

\section{Results and Discussion}

Produced composites were burned out to find out fibre volume ratios $\left(\mathrm{V}_{\mathrm{f}}\right)$. Results are given in Fig. 1. According to this, proportional results with PA powder used in suspension were obtained from composites. For 30, 40 and 50\% PA powder in suspension, 70 to $77 \%$, $56-74 \%$ and $53-69 \% V_{f} s$ obtained, respectively. Highest $V_{f} s$ were obtained from composites produced by spraying method, while lowest values were taken from composites produced by dipping+pressing method. In general, deviation from the expected values was $5 \%$ for $30 \% \mathrm{PA}, 8.3 \%$ for $40 \% \mathrm{PA}$, and $22 \%$ for $\% 50 \mathrm{PA}$. Thus, the lower the used powder ratio, the more stable the $\mathrm{V}_{\mathrm{f}}$ of produced composites were.

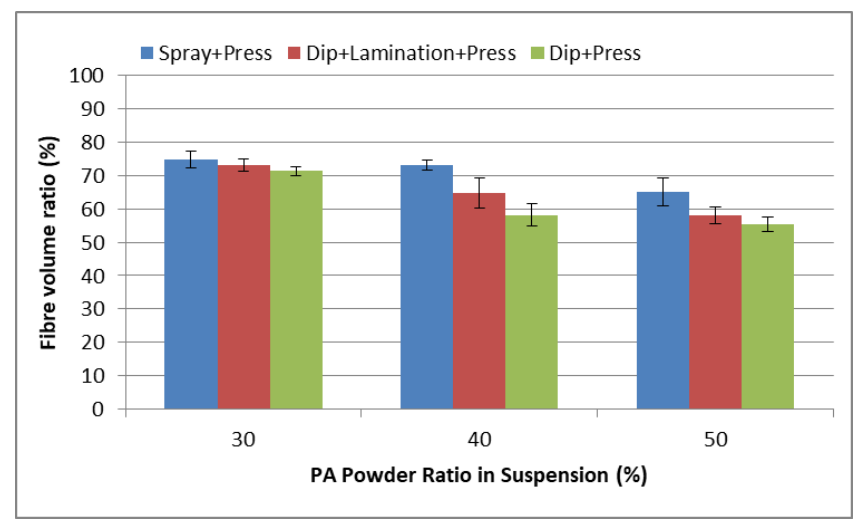

Fig. 1. Fiber volume ratios of the samples.

In Fig. 2 and 3, tensile test results were given. Although samples with 30\% PA powder ratio in suspension had higher $\mathrm{V}_{\mathrm{f}} \mathrm{s}$, ultimate tensile stress and modulus values were lower. It is possibly because of less fibre-matrix interface formation. 30\% PA matrix might inadequate to form fully wetting of fibres. As the matrix ratio increased, in other words $\mathrm{V}_{\mathrm{f}}$ decreased, tensile test results increased, especially in samples with 40\% PA ratio. However increase in tensile results did not continued in samples with 50\% PA ratio. Although sufficient wetting achieved at and over $40 \%$ PA, over $40 \%$ PA $V_{f}$ decline lead decrease in tensile test results. Therefore samples with $50 \%$ PA slightly decreased except samples produced with spray+press method. Because $\mathrm{V}_{\mathrm{f}}$ was higher than the others in same $50 \%$ group. 


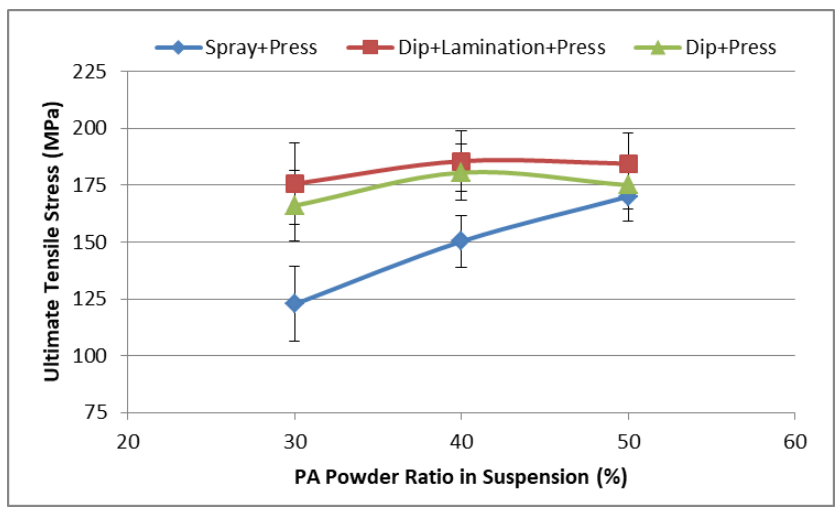

Fig. 2. Ultimate tensile stress results.

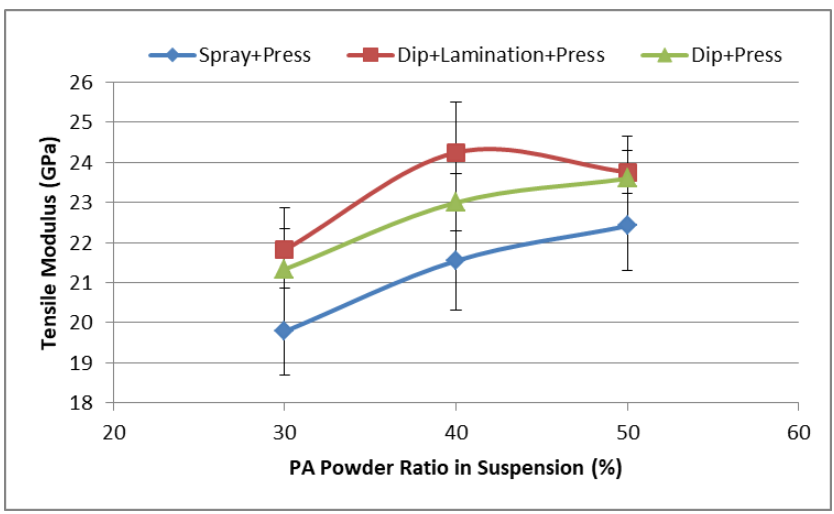

Fig. 3. Tensile modulus results.

In the study of Niforoz et al. [10], unidirectional E-glass/polyamide 6 prepregs were compression moulded at various conditions and composites were obtained at 58\% $\mathrm{V}_{\text {f. }} 397-494 \mathrm{MPa}$ tensile strength and 21-29.8 GPa tensile modulus values were determined from $\left[0_{\mathrm{n}} / 90_{\mathrm{n}}\right]_{\mathrm{s}}$ cross-ply laminates. Although we had similar modulus results with them, they achieved higher stresses. Due to woven structure leads pockets at cross-over points [11], these points may cause weakening and lead lower stress results.

Similar trends were obtained from bending test with tensile test. In Fig. 4 and 5, bending test results are seen. Here the samples produced with dipping+lamination+press had considerably higher results. Addition lamination step improved the flexural properties much.

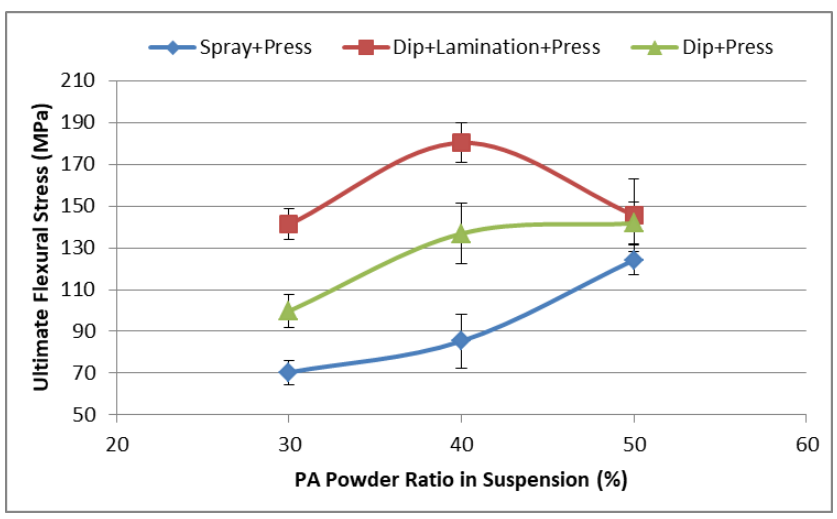


Fig. 4. Ultimate flexural stress results.

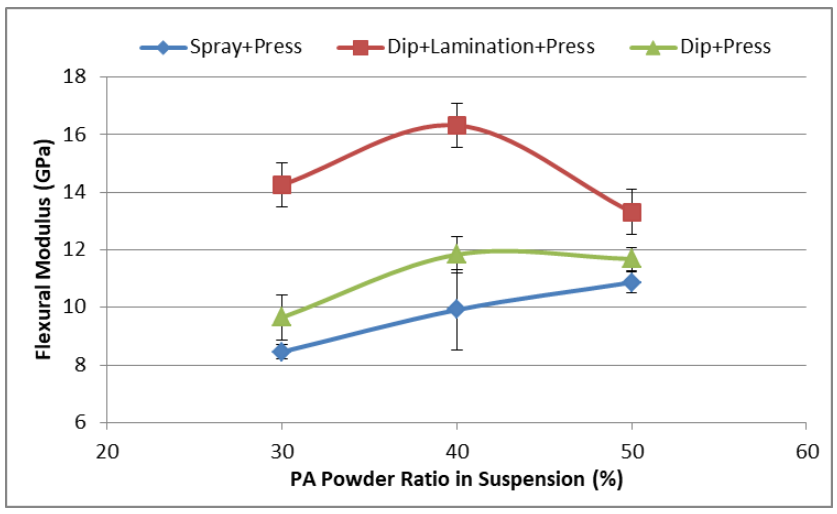

Fig. 5. Flexural modulus results.

Impact strength values as seen in Fig. 6 showed similar trends also with tensile and bending test results. Again higher values obtained with the production of dipping+lamination+press method and samples at $40 \%$ PA. Caminero et al. [12] were used fused deposition modelling technique to reinforce polyamide matrix with continuous fibres and investigated impact behaviour. They found impact strength in the range of $75-275 \mathrm{~kJ} / \mathrm{m}^{2}$ with various glass reinforcement layer thicknesses. In our study, optimum results were around $100 \mathrm{~kJ} / \mathrm{m}^{2}$, nearly in the lower limits of Caminero and et. al. findings.

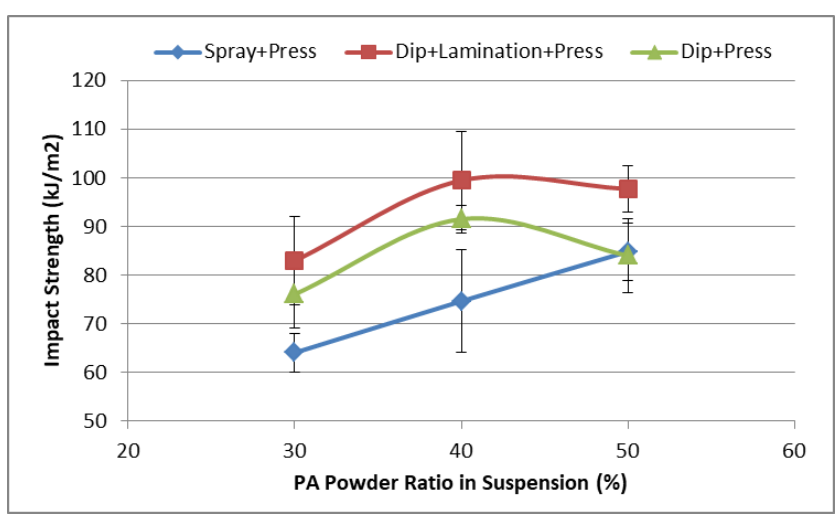

Fig. 6. Impact strength results.

After impact test, SEM observations were applied to fractured surfaces. Samples produced with Spray+Press, Dip+Lamination+Press, and Dip+Press was compared in Fig.7. Fibre failure and fibre pull-out was seen on samples. In Spray+Press, clean fibres mostly observed which is the evidence of poor interface adhesion. However there were some matrix residuals on fibres in the samples of Dip+Lamination+Press, and Dip+Press. These were also the ones which had better mechanical results than Spray+Press samples. 

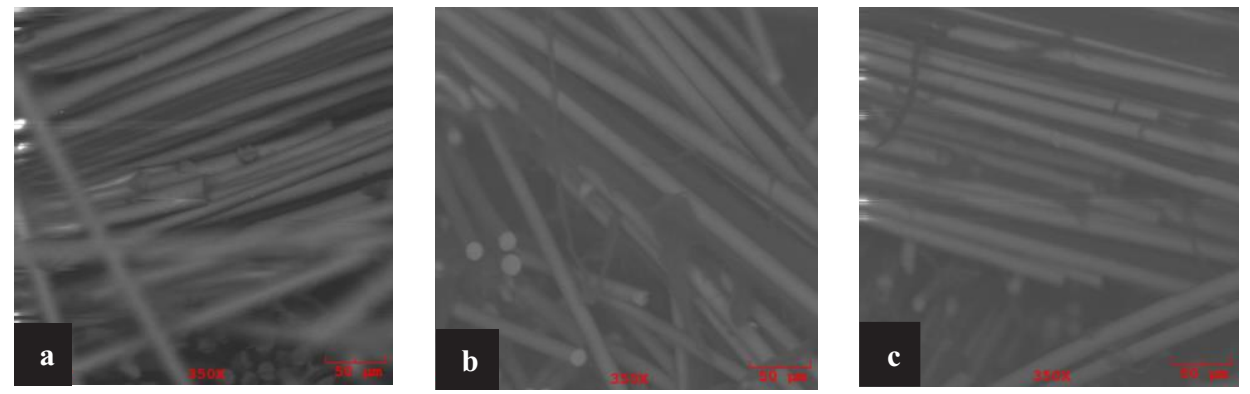

Fig. 7. SEM micrographs: a) Spray+Press, b) Dip+Lamination+Press, c) Dip+Press.

\section{Conclusions}

In this study, E-glass woven fabric reinforced PA matrix samples were produced with suspensions at 30, 40 and 50\% PA ratios. Also three production procedures were applied. These were spraying suspension to fabric, dipping fabric to suspension and additionally laminate each layer before pressing, and dipping and directly pressing without lamination. The final step was pressing for consolidation for all. Mechanical tests and burn out test were performed to obtained composites. According to these:

- $\mathrm{V}_{\mathrm{f}}$ decreased in samples with the increase in PA ratio in suspension

- Lowest mechanical results were obtained when 30\% PA used in suspension. At this ratio, $\mathrm{V}_{\mathrm{fS}}$ were higher. Thus matrix might inadequate to form well interface.

- Highest results were achieved when $40 \%$ PA used in suspension. This was possibly because of rise in matrix enabled wettability on fibres and therefore improved interface formation.

- In 50\% PA, results started to decrease slightly. Although sufficient interface formation gained at $40 \%$ PA, $V_{f}$ of the samples decreased critically that lead reduction in mechanical properties at $50 \%$.

- When methods compared with each other, sprayed samples had lowest results. In SEM observation of this group, clear fibre surfaces were observed. It indicates weak interface bonding.

- In SEM observation of dipped samples, some matrix residuals were seen in both with/without laminated groups. However, additional laminated ones showed better mechanical properties.

\section{References}

[1] F.N. Cogswell, Thermoplastic aromatic polymer composites. Oxford: ButterworthHeinemann (1992).

[2] J. Njuguna, Z. Mouti, and K. Westwood, Toughening Mechanisms in Composite Materials. Elsevier Ltd. (2015)

[3] J. L. Thomason, Comp. Sci. Tech. 59 (1999)

[4] Y. Yoo, M. W. Spencer, and D. R. Paul, Polym. 52 (2011)

[5] B. Mouhmid, A. Imad, N. Benseddiq, S. Benmedakhè Ne, and A. Maazouz, Polym. Test. 25 (2006)

[6] H. Bijsterbosch and R. J. Gaymans, Polym. Compos.16, 5 (1995) 
[7] A. Hassan, R. Yahya, A. H. Yahaya, A. R. M. Tahir, and P. R. Hornsby, J Reinf Plast Comp 23, 9 (2004)

[8] J. L. Thomason, Compos. A 39 (2009)

[9] Z. Shen, S. Bateman, D. Yang Wu, P. McMahon, M. Dell, and J. Gotama, Comp. Sci. Tech. 69 (2009)

[10] M. Nikforooza, M. Golzara, M.M. Shokrieh, and J. Montesano, Compos. A 105 (2018)

[11] D. Hull, An Introduction to Composite Materials. Cambridge University Press. (1981)

[12] M. A. Caminero, J.M. Chacon, I. Garcia-Moreno, and G. P. Rodriguez, Compos. B 148 (2018) 